\title{
Turismo rural integrado a agricultura familiar: Análise interdisciplinar da experiência do Circuito Sabiá em Matelândia - PR
}

\author{
Turismo Rural integrado a la agricultura familiar: Análisis \\ interdisciplinar de la experiencia del Circuito Sabia en Matelandia - PR \\ Rural Tourism integrated to family agriculture: Interdisciplinary analysis \\ of the Circuito Sabia experience in Matelândia - PR
}

Eder Cordeiro ${ }^{1}$

Rafael Lucas Alves Ferreira ${ }^{2}$

Jean Carlos Berwaldt ${ }^{3}$

\begin{abstract}
Resumo
Este estudo tem como objetivo descrever e analisar uma experiência de Turismo Rural integrado a agricultura familiar. Como metodologia, realizou-se uma visita in loco e entrevista a uma propriedade rural do Circuito Sabiá no Município de Matelândia do Oeste do Paraná. Com esta pesquisa verificamos que a prática do Turismo Rural na propriedade analisada, contribui para o fortalecimento da agricultura familiar bem como o estimulo de práticas de preservação e educação ambiental.
\end{abstract}

Palavras-Chave: Turismo Rural; Agricultura Familiar.

Resumen

Este estudio tiene como objetivo describir y analizar una experiencia de Turismo Rural integrado a la agricultura familiar. Como metodología, se realizó una visita in loco y entrevista a una propiedad rural del Circuito Sabiá en el Municipio de Matelandia del Oeste de Paraná. Con esta investigación verificamos que la práctica del Turismo Rural en la propiedad analizada contribuye al fortalecimiento de la agricultura familiar así como el estímulo de prácticas de preservación y educación ambiental.

Palabras claves: Turismo rural; Agricultura familiar.

\begin{abstract}
This study aims to describe and analyze a rural tourism experience integrated to family farming. As a methodology, an on-site visit and interview to a rural property of the Circuito Sabia in the Municipality of Matelândia of the West of Paraná was carried out. With this research we verified that the practice of Rural Tourism in the property analyzed, contributes to the strengthening of family agriculture as well as the stimulation of practices of preservation and environmental education.
\end{abstract}

\footnotetext{
${ }^{1}$ Mestrando em Desenvolvimento Rural Sustentável; Universidade Estadual do Oeste do Paraná; Foz do Iguaçu, Paraná, Brasil; ederiped@ @otmail.com.Trabalho apresentado no I Seminário Latino-Americano de Estudos em Cultura - SEMLACult, Foz do Iguaçu/PR, Brasil, 2017.

${ }^{2}$ Mestrando em Desenvolvimento Rural Sustentável; Universidade Estadual do Oeste do Paraná; Foz do Iguaçu, Paraná, Brasil; rafaeldrsa@gmail.com.

${ }^{3}$ Mestrando em Desenvolvimento Rural Sustentável; Universidade Estadual do Oeste do Paraná; Foz do Iguaçu, Paraná, Brasil; tytho_tytho@hotmail.com.
} 
Keywords: Rural tourism, family farming;

\section{Introdução}

O presente estudo refere-se ao tema da prática do turismo rural ou turismo no espaço rural pela agricultura familiar, temática ainda pouco conhecida, mas que, entretanto, vem ganhando relevância enquanto uma estratégia de reprodução social, cultural e econômica na agricultura familiar. De acordo com Tulik (2006) a experiência europeia foi imprescindível para aquecer o debate do Turismo no Brasil, de modo que, muitos dos termos e expressões utilizadas para referencia-lo foram importados da Europa.

Ao considerar o Brasil portador de uma agricultura familiar totalmente diversificada em seus aspectos culturais, sociais e produtivos, temos a conformação de práticas de Turismo Rural com características especificas a realidade do perfil heterogêneo do espaço rural brasileiro. Neste sentindo integrar a prática do Turismo Rural a agricultura familiar surge como pauta nas bases institucionais de governo.

No dia 31 de maio de 2006 o Governo do Paraná promulgou a Lei 15.143, estadual do Turismo Rural na Agricultura Familiar que conceitua a atividade turística desenvolvida pelos agricultores familiares. "O turismo deve ser tratado como um instrumento capaz de contribuir para o fortalecimento da agricultura familiar e o seu desenvolvimento está condicionado à sua inserção em um contex to que reforce e privilegie os valores éticos, econômicos e culturais dos agricultores familiares (SEAB PR)".

A base do Turismo Rural na Agricultura Familiar (TRAF) nada mais é do que a relação entre o desenvolvimento rural sustentável e a cultura local do agricultor familiar. Essa aliança fomenta a agroecologia, ou seja, o cultivo de produtos orgânicos, a pecuária tradicional e a preocupação na conservação dos recursos naturais. E proporcionando aos envolvidos outra opção de fonte de renda da comunidade (EMBRATUR, 2016). O turismo rural é definido como o conjunto das atividades turísticas desenvolvidas no meio rural, comprometidas com a produção agropecuária, agregando valor a produtos e serviços, resgatando e promovendo o patrimônio cultural e natural.

Tendo como bases as características do turismo rural, este estudo possui como objetivo, descrever e analisar uma experiência de Turismo Rural pela agricultura familiar no Município de Matelândia- PR. 


\section{Metodologia}

Essa pesquisa foi realizada em uma Comunidade Rural no Circuito Sabiá (Figura 1) a propriedade escolhida para estudo foi da família Grassi localizada no município de Matelândia, Macrorregião Oeste do Estado do Paraná. A figura abaixo mostra a localização da propriedade que foi realizado o estudo.

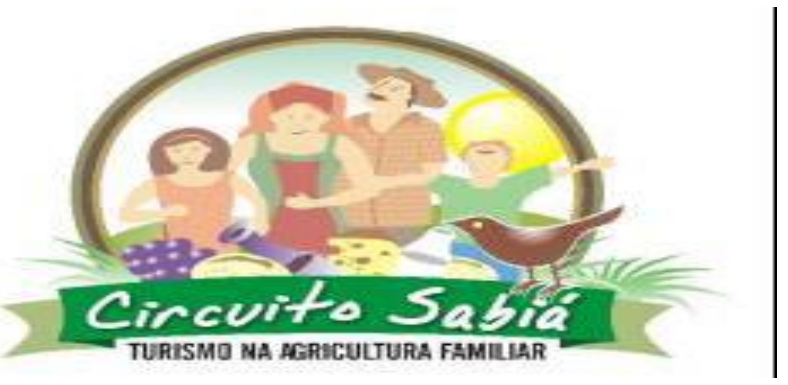

Figura 1 - Logomarca do Circuito Sabiá Fonte: Turismo Matelândia, 2016.

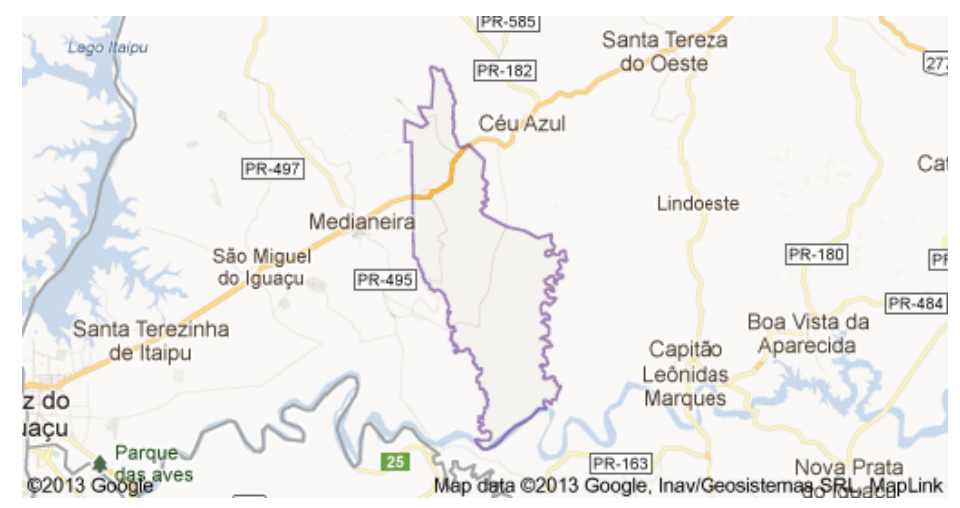

Figura 2 - Mapa da localização do Circuito Sabiá Fonte: Turismo Matelândia, 2016.

A propriedade da família Grassi faz parte das atividades de turismo rural de Matelândia, oferecendo almoços, café da manhã e pousos para grupos pequenos. No Circuito Sabiá cada propriedade que faz parte do roteiro tem a finalidade de oferecer um produto ou seja, uma prestação de serviço diferenciada das demais. A propriedade do senhor Grassi faz parte dos municípios lindeiros e também do Programa Cultivando Água Boa, o qual desenvolve projetos de preservação de nascentes e educação ambiental na Bacia do Paraná III. Esta pesquisa possui caráter qualitativa, de cunho analítica, cujos dados são descritos conforme sua situação, com o objetivo de compreender, em seus próprios termos, os fenômenos aqui apresentados (GOLDENBERG, 2000). Em relação aos aspectos práticos 
deste estudo, foi realizado uma visita in loco na propriedade para entrevistar os proprietários e as pessoas que trabalham na propriedade.

Para esse estudo também se aplicou a metodologia interdisciplinar de estudos para ter vários olhares referente a inovações tecnológicas e o turismo rural na propriedade. Conforme indicado por D’Ambrósio (2004), a prática da interdisciplinaridade é interessante, necessária diante da tensão que se acumula entre as disciplinas e acaba por criar outros campos de investigação, como ocorreu no século XIX. Porém, esses campos são assentados na lógica das disciplinas, avançando para que elas mesmas se tornem outras disciplinas, estabelecidas segundo a lógica disciplinar.

\section{Resultados e Discussões}

O Turismo rural em Matelândia mediante as observações realizadas in loco, reflete os aspectos simbólicos e atrativos do circuito sabia onde está inserida a propriedade da família Grassi, composto por propriedades agroecológicas o que estimula nos turistas um olhar diferenciado para espaço rural, enquanto um espaço de vivência (Wanderley, 2009) e para as questões ambientais. Estimulando reflexões, que o espaço rural vai para além dos aspectos do ponto de vista agrícola, que existe relações sociais, culturais, econômicas e ambientais constituídas. Em relação aos dados levantados na pesquisa nota-se que o Turismo Rural na agricultura familiar tem gerado muitos benefícios para os agricultores familiares é um atrativo para que mais pessoas conheça o meio rural. Na propriedade do senhor Grassi, mantém as tradições do homem do campo isso fica evidente na sua primeira fala no momento da acolhida mostra a preocupação da verdadeira preservação dessa identidade isso fica nítido em suas palavras:

\footnotetext{
“Quem já 'viveu na roça', como dizem, ou mesmo quem deseja ter uma experiência diferente, tem em algumas opções de passeio a chance de conviver um pouco com alguns costumes e beneficios da vida no campo". (GH)
}

Essa fala nos remete a questão do êxodo rural que ocorreu na agricultura onde muitas pessoas que estão nas cidades hoje tiveram a sua história com agricultura nota-se o convite que o mesmo faz para que as pessoas possam ter a experiência que teve no passado com agricultura.

A história do turismo rural nessa propriedade ocorreu através dos programas sociais e do o incentivo da Itaipu para o turismo rural na agricultura familiar, uma das falas do senhor Grassi nos mostra como foi o início do seu trabalho com essa atividade na agricultura:

"O início tudo aqui foi uma nascente da Itaipu, que iniciou tudo ali”. Então, aqui foi a primeira nascente da Itaipu, cultivando Água Boa quando eles formaram o 
Cultivando Água Boa, então dentro desse projeto Cultivando Água Boa, tinha o projeto do turismo rural, Turismo Rural na Agricultura Familiar. Então eles vieram e fizeram várias reuniões no pavilhão e tal, e daí foram de família por família, $e$ acabaram parando aqui, e foram ver que tinha ali, e acataram que nós tínhamos (SIC) condições de mexer o turismo rural, nada de mexer com as coisas é o que nós tínhamos aqui e várias reuniões com o presidente da Itaipu gente de tudo quanto foi lado. E daí nós começamos a fazer almoço para o pessoal da Itaipu, pessoal da cidade. Veio até o chefe do turismo de Brasília, do Brasil inteiro veio aqui e deram todas as condições, e a prefeitura acatou a proposta, e fomos indo, fomos evoluindo "ai entrou outras familias" (GH).

Através dessa fala podemos perceber que fica evidente que nos dias atuais mesmo a propriedade sendo da agricultura familiar e como se fosse uma empresa o turismo rural requer cuidados pois tem que oferecer atrativos a mais que uma propriedade comum essa era uma das grandes preocupações do senhor Grassi ao analisar essa fala percebe um espírito de empreender que essa família tem de aceitar a ideia e o desafio e mergulhar de cabeça numa proposta que muda toda a história da agricultura tradicional.

Trabalhar com agricultura tradicional e basicamente uma relação entre o agricultor e sua propriedade, mas ao abrir as portas dessa propriedade para receber turistas muda a realidade e todos os dias praticamente ter pessoas diferentes dentro do seu recinto e si adequar as exigências e as mudanças que o mercado tem.

Diante da visita in loco pode-se chegar a seguinte conclusão que a propriedade se encontra em condições para receber os turistas e a mesma está verdadeiramente preparada para o turismo rural. Isso é possível constatar pelos os vários atrativos que a mesma apresenta pode citar aqui como exemplo uma das coisas que chama muita atenção na visita da propriedade um porão antigo que tem como finalidade servir as refeições nesse porão encontra-se vários objetos que para o senhor Grassi são considerados tesouros que na realidade são considerados a história da família e foram utilizados pela os membros da família que vai desde utensílios domésticos a objetos de trabalho na lavoura alguns trazidos pela a família desde da aquisição da propriedade que já faz várias décadas.

$\mathrm{Na}$ propriedade observa-se alguns objetos como serrote, traçador, ferro de passar, placa do primeiro carro que a família adquiriu alguns barris que foram trazidos pela a família para a fabricação de vinho moinho de café, um reio feito de couro, ratoeiras, freio de cavalo, esporas, objetos de colocar farinha confeccionando pelo os índios e vários outros.

Fazer uma releitura desses objetos e como ler a história da família, ou seja, entrar no "seio" da família e penetrar na cultura da família, o valor que esses objetos possuem é muito mais que um valor material, configurando-se em valor sentimental que é muito maior, sem falar que deixa o ambiente decorado e prende atenção dos visitantes, na sua fala claro o carinho e a valorização que o mesmo tem por esses objetos. 
"Esses objetos não sai daqui enquanto estiver vivo já me ofereceram muito dinheiro pelo os mesmos, mas não estão à venda é de um valor sentimental muito grande" $(G H)$.

Toda atividade no início tem suas dificuldades seus medos e seus anseios uma preocupação muito grande no início da atividade da família Grassi foi à questão da qualificação profissional para receber os turistas para o turismo rural como mostra na fala:

"Para receber, a gente tem que estar preparada. Fizemos vários cursos,
conhecemos vários lugares. Fomos conhecer outros lugares, como em Santa
Catarina, na acolhida colônia, aonde vimos os galpões tudo com máquinas
modernas, não tinham uma sombra em roda das casas, àquelas casas tudo plantado
soja" (GH).

Ao analisarmos essas palavras destacamos uma reflexão em relação a preocupação com o desenvolvimento rural sustentável e principalmente com a educação ambiental, nessa fala fica nítido o cuidado pela a preservação ambiental da propriedade podendo chegar à conclusão que essa questão ambiental também atrai os turistas para visitar a propriedade. Cabe ressaltar aqui que para o sucesso as participações de cursos foram imprescindíveis, o que levou capacitação e qualificação a família para atividade, isso fez que a mesma tivesse noções de administração e de acolhida como mostra a fala a seguir:

\footnotetext{
"Aqui em Matelândia, fizemos vários cursos o professor Jacó do SENAR, começou desde o de Olho na Qualidade, até último que foi o de atendimento, acolhida, como receber melhor os visitantes e o manuseio dos alimentos" (GF).
}

A gastronomia oferecida no roteiro do turismo rural possui características particulares, onde grande parte dos produtos são produzidos na propriedade de forma orgânica e o que não é produzido na propriedade e comprado, mas sempre preservado o cuidado da qualidade dos alimentos sendo tudo produzido de forma orgânica. Em relação à produção na sua propriedade o senhor Grassi relata que:

"Hoje aprendi o quando o agrotóxico faz mal, produzimos alimentos com qualidade para oferecer qualidade às pessoas uma alimentação diferenciada daquela do dia a dia que vocês têm em suas casas" (GH).

Ao questionar em relação aos cursos referentes a custos, que para agricultura familiar essa formação financeira e muito importante pois a propriedade rural de forma geral acaba se configurando com características empresariais em que a família deve possuir noções de gestão e administração se torna necessário o conhecimento de custos, o relato abaixo mostra a participação em cursos dessas áreas. 
RELACult - Revista Latino-Americana de Estudos em Cultura e Sociedade

Revista Latinoamericana de Estudios en Cultura y Sociedad | Latin American Journal of Studies in Culture and Society V. 03, ed. especial, dez., 2017, artigo $n^{\circ} 608$ | relacult.claec.org | e-ISSN: 2525-7870

“A gente já fez os cursos, custos, os cálculos, eu não posso dizer que eu viveria hoje só do turismo, pois quero preservar a tradição da agricultura e o que não utilizamos no turismo rural mandamos para a cidade e consumismo para o nosso próprio gasto, ou seja, nossa alimentação dia a dia” (GF).

Através do relato fica evidente a preocupação com a qualificação profissional de receber bem, de estar preparado para receber o turista, percebe-se a partir desta fala que não existe apenas uma preocupação com a estrutura do local, mas existe um cuidado todo especial com questões de acolhida de receber bem, isso se faz necessário para que o turista possa se sentir bem e divulgar a propriedade para outras pessoas.

Em relação as atividades de produção agrícola a família Grassi cultiva a produção de uvas, a qual também faz parte do roteiro do turismo rural da propriedade, que em seu período de produção é possível oferecer a seus turistas uma atividade diferenciada conhecida como colhe e paga a mesma é muito atrativa os turistas vão até a parreira faz a sua colheita e paga aquilo que colheu. Em Matelândia apresenta-se um número de propriedades que estão inseridas no turismo rural e que fazem faz parte do Circuito do Sabiá (Figura 3), criado em 2005 esse nome deu-se pela proximidade com o Rio Sabiá, que corta a cidade. Nesse circuito as propriedades estão preparadas para receber os turistas tanto na questão do acolhimento bem como na questão de estrutura.

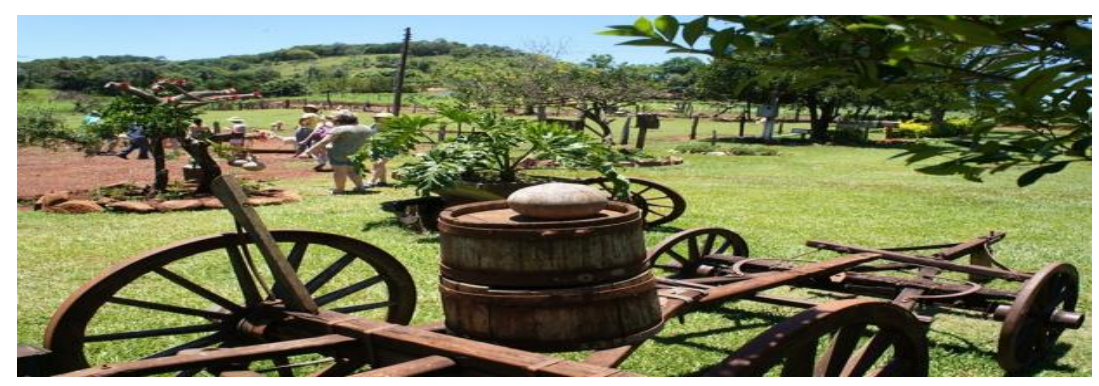

Figura 3 - Circuito Sabiá, propriedade da família Grassi, jardim da casa.

Fonte: Autores, 2016.

Outro ponto que destaca na propriedade é sua preservação ambiental (Figura 4) principalmente das nascentes as quais foram recuperadas totalmente. Cabe ressaltar aqui que nessas visitas do Circuito Sabiá não ocorre apenas a prática do turismo rural, como também temos a ocorrência de uma boa aula de Educação Ambiental, o que percebemos de acordo com a fala a seguir: 
"Bom pessoal eu vou dizer a verdade essa água eu conheço há 55 anos, o que era esse rio na época ele tinha trinta por cento a mais do que e normal aqui, e aos vinte anos ou vinte e cinco atrás ele virou a metade disso aqui eu sou testemunha disso aqui, todo mundo depredou a nascente ninguém preservou nada e ela foi se indo com o tempo todo o pessoal como eu também estava pensando nesse projeto de recosta onde preservei minhas nascentes com o Cultivando o Agua Boa o bicho pegou aceitamos o desafio e hoje me sinto muito feliz por fazer parte desse projeto que recuperou meu rio minha propriedade os trinta metros de cerca para mim não teve problema nenhum e nem acabar com meu chiqueirão de porco" $(G H)$.

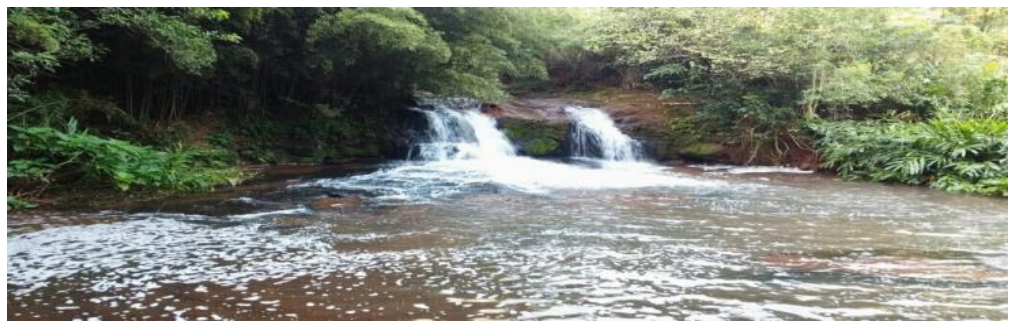

Figura 4- Rio e as nascentes, proteção ambiental

Fonte: Autores, 2016.

Essas falas mostra a riqueza de conteúdo em relação a preservação ambiental e memórias afetivas que essa família possui, a experiência exitosa de desenvolvimento rural sustentável é nítida nessa propriedade evidenciada nas falas e na forma que se pode enxergar durante a visita da propriedade.

Através dessa discussão fica evidente o quanto essa propriedade é fundamental para o turismo rural e para a prática de educação ambiental a mesma proporciona turismo e vários benefícios cabe ressaltar aqui a importância e as contribuições que o programa agua boa traz o apoio e o incentivo ao grupo de produtores.

\section{Conclusões}

O turismo rural na propriedade da família Grassi contempla uma dimensão antropológica, visto que oportuniza aos visitantes vivenciarem aspectos do cotidiano da vida rural na propriedade, seja por meio do contato com a natureza, o contato com uma alimentação confeccionada por produtos locais, permitindo uma relação diferenciada de produtor e consumidor a partir de um contato mais próximo. A visitação por meio do turismo rural na propriedade extrapola as questões apenas econômicas, assume uma nova lógica, por meio de elementos simbólicos, como a valorização do saber local.

Outro ponto chave neste estudo é destacar o quanto a propriedade é relevante para além da prática do turismo rural, a de educação ambiental, a qual permite aos visitantes 
refletirem sobre suas práticas cotidianas e perceberem a importância de proteger o meio ambiente.

\section{Referências}

BRASIL, Instituto Brasileiro de Turismo - EMBRATUR. Manual Operacional do Turismo Rural. Brasília: EMBRATUR, 2016.

D’AMBRÓSIO, U. Prefácio. In: BORBA, M. C.; ARAÚJO, J. L. (Org.) Pesquisa Qualitativa em Educação Matemática. Belo Horizonte: Autêntica, 2004.

GOLDEMBERG, M. A arte de pesquisar: como fazer pesquisa qualitativa em Ciências sociais. Rio de Janeiro, Ed. Record, 2000.

TULIK, O. Turismo no espaço rural: segmentação e tipologia. In: ALMEIDA, Joaquim Anécio; SOUZA, Marcelino. (Org.). Turismo Rural: patrimônio, cultura e legislação. Santa Maria: FACOS/UFSM, 2006. p. 107-119.

Secretaria da Agricultura e Abastecimento (SEAB). Disponível em: www.agricultura.pr.gov.br. Acesso em: 15 maio de 2016.

WANDERLEY. M. N. B. Agricultura familiar e campesinato: rupturas e continuidades. In: WANDERLEY. M. N. B. O mundo rural como espaço de vida: reflexões sobre a propriedade da terra, agricultura familiar e ruralidade. Porto Alegre. Ed. da UFRGS, 2009. (p.185-200). 